\title{
Validation of a Detached Eddy Simulation (DES) Model in Complex Urban Environment
}

\author{
By Rallou Eleni Dadioti* \\ Simon Rees ${ }^{\dagger}$
}

\begin{abstract}
This paper examines the performance of the Detached Eddy Simulation (DES) turbulence model implemented in the open source CFD library OpenFOAM for external flows in complex urban environments. The aim of this work is to provide a validation study of the DES, using an opensource CFD library, in order to make such calculations accessible and affordable. For these purposes we revisit a number of benchmark data sets developed by the Architectural Institute of Japan. We firstly present the results for the analysis of the flow around a single high rise building and make comparisons with wind tunnel data in order to give confidence to the DES implementation. Secondly we examine the prediction capabilities of DES for a flowfield in an actual urban environment, in a sub-central area in Shinjuku Tokyo, where high rise buildings and low rise houses are found close together. Using data derived from wind tunnel experiments and field measurements as well, we conduct the comparison studies and we find that the DES results show significantly better prediction of wind flows in comparison to other approaches.
\end{abstract}

Keywords: Built Environment, Computational Fluid Dynamics, Micro wind turbine, Wind energy

\section{Introduction}

\section{CFD in Urban Environment}

The calculation of external flows in complex urban environments is challenging. Figure 1 shows a flow pattern about a single building. Separation on the top and sides of the building, vorticity in this separated flow, vortex in front and around the building, horseshoe shape downwind, stagnation regions and reattachment zones are some of the effects of the interaction between the wind flow and buildings. The unsteadiness of the flow after the wind strikes on the buildings makes the evaluation of the wind flow cumbersome and analytical methods usually fail to examine the complex relationships between the variables (Stathopoulos and Baniotopoulos, 2007).

${ }^{*}$ PhD Researcher, De Montfort University, UK.

${ }^{\dagger}$ Reader, De Montfort University, UK. 
Figure 1. Mean Streamline Patterns about a Building (Woo et al., 1977; Peterka et al., 1985)

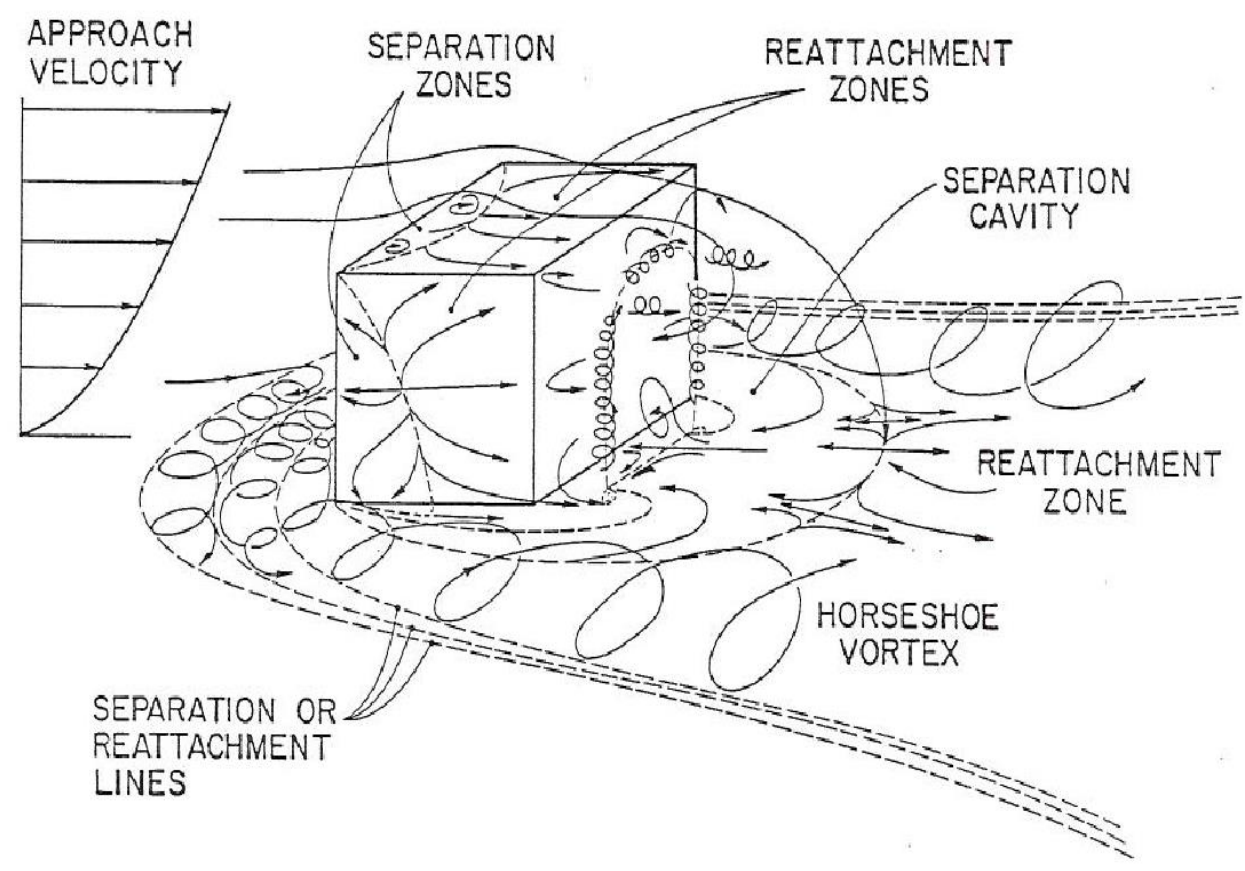

Wind tunnel testing demonstrates good results and it has been used and developed successfully since the end of the 19th century. However, it is not pliable to adjustments and its remodeling requires a long time and effort. It can only capture the flow characteristics at discrete points using sensors, the cost of which is a restraint for a broader use other than the universities and large international companies (Mcalpine, 1985). Computational Fluid Dynamics is a promising tool; the models can be altered quickly and compute the flow over the whole domain. With the outstanding recent progress in computing, the feasibility of the CFD analysis in reasonable time is a reality and a high performance PC desktop can be used instead of the mainframe computers. Furthermore, open source CFD libraries have the potential to make such calculations accessible and affordable. CFD has been progressively applied to a wide range of studies in urban environments; including structural loads (Colloquium, 2013; Katz and Ag; Meroney et al., 2001; Mohotti et al., 2014), pedestrian comfort (Janssen et al., 2013; Fadl and Karadelis, 2013; Blocken et al., 2012; Blocken and Persoon, 2009; Willemsen and Wisse, 2007; Meroney et al., 2001), natural ventilation (van Hooff et al., 2011a; Hooff and Blocken, 2010), contaminant dispersion (Holmes and Morawska, 2006; Coirier and Kim, 2006; Vardoulakis et al., 2003), wind energy (Anjum, 2014; Rasouli et al., 2014; Tabrizi et al., 2014; Gagliano et al., 2013; Irshad, 2012; Kalmikov et al., 2010; Probst and C'ardenas, 2010; King, 2009; Milanese et al., 2011) and other problems (Neofytou et al., 2006; van Hooff et al., 2011b; Huang and Li, 2010; Tominaga et al., 2011). However, CFD results are not always valid and harmonised with the real world results. In certain circumstances they can be erroneous and validation testing -the process of determining the degree to 
which a model is an accurate representation of the real world from the perspective of the intended uses of the model (AIAA, 1998) - is required. The key validation procedure incorporates the comparison between the computational results and the experimental data (Figure 2). In this work we examine the performance of CFD models -implemented using the OpenFOAM CFD library- using benchmark data derived from both wind tunnel data and field measurements.

\section{OpenFOAM}

OpenFOAM is a free, open-source CFD software library, that makes use of the object oriented features of the $\mathrm{C}++$ programming language (Jasak et al., 2007). It was released in 2004 and since then, it further developed and gradually gained popularity in both commercial and academic organisations, the reward of being free of charge and became easily modifiable and adequate for a broad range of fluid dynamic applications. It also provides massive parallel computing capabilities and the possibility for someone to easily implement his own solvers and functions (Ghione, 2012). However, despite the considerable advantages, the downsize of OpenFOAM is the lack of the quality certification and documentation. The development of independent quality assurance data and documentation relies on the efforts of third parties. Some validation exercises where OpenFOAM models have been applied to wind flows have been published by Balogh et al. (2012); Churchfield and Moriarty (2010); Flores et al. (2014) but these have not been concerned with urban environments.

Figure 2. Validation Process (Oberkampf and Trucano, 2002)

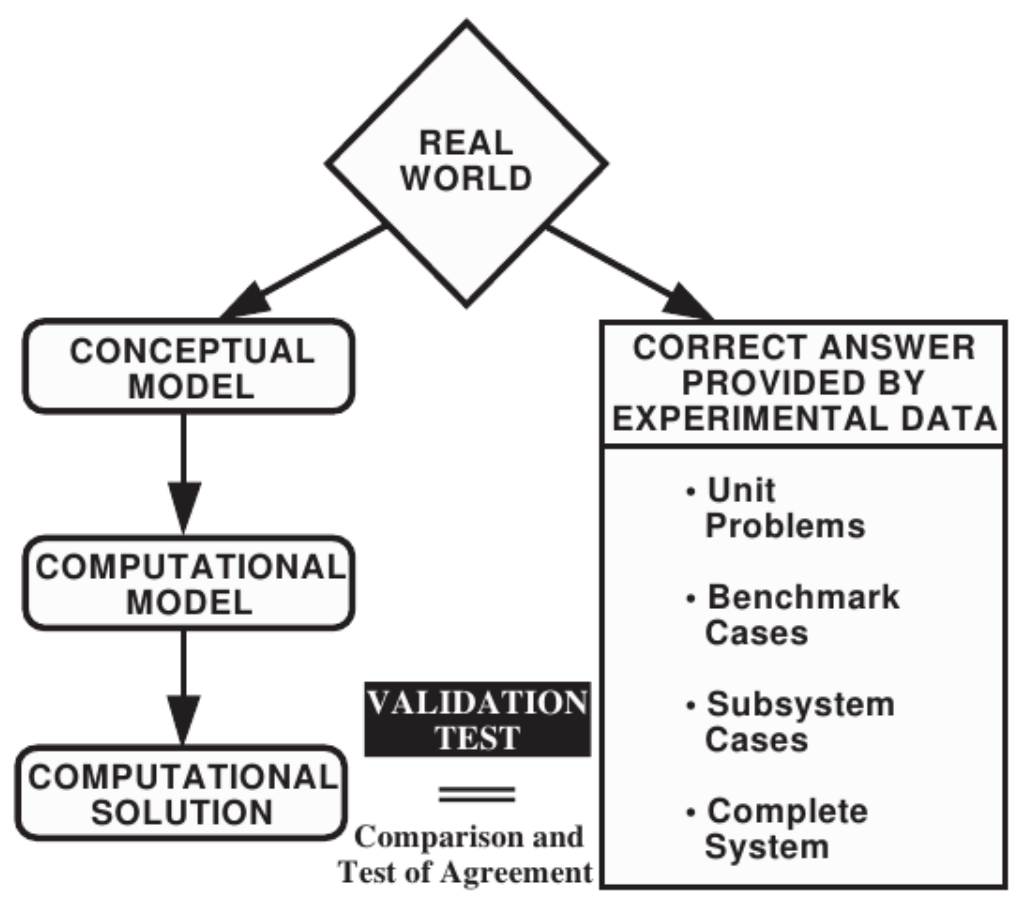


In applying the first of the AIJ test cases we have used the steady-state RANS solver simpleFoam from the OpenFOAM library (version 2.3.1) with the standard k- $\varepsilon, \mathrm{k}-\omega-\mathrm{SST}$ and Realizable k- $\varepsilon$ eddy viscosity turbulence models (Launder and Spalding, 1974; Menter, 1994; Shih, 1994). In the second test case involving a model of a real urban environment, we have applied the standard k-" model for the RANS calculations. The DES concept was developed by Spalart et al. (1997) for aerospace applications, involving boundary layer separation. The DES model we have applied in both test cases is the DDES-SA model (Spalart et al., 2006) with the pisoFoam transient solver. This version of the Spalart-Allmaras DES model has some improvements compared to the original model (Spalart et al., 1997). These developments seek to improve the prediction of the boundary layer separation points on aerofoils. This is not a particular issue in building external flows since separation is generally forced by reverse right-angle features at roof and wall edges rather than curved surfaces.

The main advantage of DES approaches in the case of the urban wind flows is that coarser grids and larger timesteps can be taken, that would otherwise be required for true LES. We see the ability to capture the features of wake regions, by calculations in LES mode, to be the most significant advantage in these types of problems, since buildings in dense urban environments are generally in the wake of neighbouring buildings rather than clean atmospheric boundary layer conditions.

\section{CFD Numerical Models}

The basis of the Computational Fluid Dynamics are the fundamental governing equations of fluid flow, known as Navier Stokes equations, named after Claude-Louis Navier and George Gabriel Stokes. They are partial differential equations describing three basic physical principles: the conservation of mass (1), the Newton's Law of Motion (2) and the conservation of energy (3) (Wendt et al., 1996).

(1) $\frac{\partial \rho}{\partial t}+\nabla \cdot \rho \boldsymbol{u}=0$

(2) $\frac{\partial \rho u}{\partial t}+\nabla \cdot(\rho u u)=-\nabla p+\nabla \cdot(\mu \nabla u)+f$

(3) $\frac{\partial \rho e}{\partial t}+\nabla \cdot(\rho u e)=-\nabla p u+\nabla \cdot(\mu u \nabla u)-\nabla q$

Considering an incompressible flow and assuming the absence of gravity and body forces, results in the formation of the Navier-Stokes equations as described in equations 4 and 5. The energy equation can be omitted and only the unknown quantities of velocity and pressure remain.

(4) $\nabla \cdot \boldsymbol{u}=0$ 
(5) $\frac{\partial u}{\partial t}+\nabla \cdot(u u)=-\frac{\nabla p}{\rho}+\nabla \cdot(v \nabla u)$

A numerical integration of the Navier-Stokes equations that directly solves the flow without any modeling, and captures all the spatial and temporal scales of the flow is known as Direct Numerical Simulation (DNS). Its advantage to provide exact, analytic solutions unaffected by approximations, at all points of the computational domain and all times of the simulated period requires a high resolution grid and costs massive computing resources and time, preventing DNS from being used in wind engineering and in complex urban environment problems (Rudman and Blackburn, 2006).

Given this constraint, only the most important - geometry dependant and high energy containing - large eddies can be explicitly calculated, while modeling the influence of the more universal small scales (Moin and Mahesh, 1998; Moeng and Sullivan, 2015). The Large Eddy Simulation (LES) spatially filters the Navier-Stokes equations $(6,7)$ to exclude small scales of the solution. The turbulent length scales larger than $\Delta$ are retained in the flow field, whereas the smaller scales, the Sub-Grid Scales (SGS) should be modeled. Despite this, this approach reduces the computational demands and the simulation of atmospheric high Reynolds number flows is still expensive in the sense of the computational cost (Breuer et al., 2003).

(6) $\frac{\partial \bar{u} i}{\partial x i}=0$

(7) $\frac{\partial \bar{u} \bar{i}}{\partial t}+\frac{\partial}{\partial \bar{x} j}\left(\bar{u}_{i} \bar{u}_{j}\right)=-\frac{1}{\rho} \frac{\partial \bar{p}}{\partial x i}+\frac{1}{\rho} \frac{\partial \tau i j R}{\partial x j}+v \nabla^{2} \bar{u}_{i}$

The oldest and most commonly used approach to turbulence modeling are the Reynolds-averaged Navier-Stokes (RANS) equations (8, 9) for incompressible flows) that are based on Reynolds decomposition. They involve the separation of each instantaneous quantity into their time-averaged part to return the statistically steady solution of the flow variable and their fluctuating component, which has to be modeled (10).

(8) $\frac{\partial U}{\partial x i}=0$

(9) $\frac{\partial \mathrm{Ui}}{\partial \mathrm{t}}+\frac{\partial}{\partial \mathrm{xj}}\left(\mathrm{U}_{\mathrm{j}} \mathrm{U}_{\mathrm{i}}\right)=-\frac{1}{\rho} \frac{\partial \mathrm{P}}{\partial \mathrm{xi}}+\mathrm{v} \frac{\partial 2 \mathrm{Ui}}{\partial \mathrm{xj} \mathrm{xi}}+\frac{\partial \bar{u} \mathrm{i}, \bar{u} \mathrm{j}^{\prime}}{\partial \mathrm{xj}}$

(10) $\mathrm{u}_{\mathrm{i}}=\mathrm{U}+\mathrm{u}_{\mathrm{i}}{ }^{\prime}$

However, even the most sophisticated turbulence models are not able to sufficiently reproduce the unsteady characteristics of the flow field, resulting in an inadequate description of unsteady phenomena (Breuer et al., 2003; Franke et al., 2004). 
In order to better capture the dynamics of turbulent complex flows using feasible computational costs, the unsteady RANS (URANS) has been introduced. The Navier-Stokes equations in order to have incompressible flow have to be time-filtered; all scales smaller than a characteristic time period $(\mathrm{t})$ are averaged and the unsteadiness accounts for time scales larger than $t$. For the averaging to make sense, the averaging period should be much smaller than the time scale of the unsteady mean motion and at the same time, the time period should be orders of magnitude higher than the time scale of the random fluctuations. However, in many fluid flow problems these requirements cannot be met simultaneously, leading to the so-called spectral problem (Sadiki et al., 2006).

To deal with the limitations of the numerical models, a new approach, known as Detached Eddy Simulation (DES), was created. It combines the Spalart- Allmaras (S-A) RANS model and the LES by means of the length scale which is defined by $l_{D E S}=\min \left(d_{\omega}, C_{D E S} \Delta\right)$, where $d_{\omega}$ is the distance to the wall involved in the destructive term of the $\mathrm{S}$-A model, $\mathrm{C}_{\mathrm{DES}}=0: 65$ and $\Delta$ is the largest local grid-spacing. Its intention is to treat the whole boundary layer using the RANS model $\left(\mathrm{d}_{\omega}<\mathrm{C}_{\mathrm{DES}} \Delta\right)$ and implement an LES model at regions of separated flows $\left(\mathrm{dw}>\mathrm{C}_{\mathrm{DES}} \Delta\right)$.

\section{Aims and Objectives}

The aim of this study is to offer some validation evidence for the DDES approaches applied to external flows in urban environments and evaluate the advantages of the DDES models in comparison to other turbulence models. For these purposes we examined the performance of both steady RANS models as well as Delayed Detached Eddy Simulation approaches implemented in OpenFOAM software (Weller et al., 1998) using benchmark data derived from wind tunnel data as well as data derived from field measurements developed by the Architectural Institute of Japan (AIJ) (AIJ, 2009; Yoshie et al., 2007). A number of studies have previously been reported that make use of these test cases Tominaga et al. (2004). This work has been carried out in the context of study and development of CFD based methods for wind energy assessment in complex urban environments. Hence we commented on the modeling of wake conditions rather than the evaluation of surface pressures and forces or dispersion of contaminants.

\section{Test Case A: High Rise Building}

\section{General Description of the Experiment}

The first test case is a study of the flowfield around a high-rise building of 2:1:1 (height:width:depth) ratio, placed in a turbulent boundary layer (Figure 3 ). The wind tunnel scale model was $0.16 \mathrm{~m}$ high and $0.08 \mathrm{~m}$ square. The wind tunnel imposed an inlet condition approximating a power law velocity profile 
with an exponent of around 0.27 and the Reynolds number was 2:4 x $10^{4}$ (Figure 3).

Measurements were taken using a split-film probe for the instantaneous wind velocity in each direction and the average and standard deviation of fluctuating wind velocities were reported (Yoshie et al., 2007). Measurements of the velocities were made at a grid of points over a vertical cross-section and on horizontal planes as indicated in Figure 4. The data used in our first validation study is that published by Meng and Hibi (1998).

Figure 3. 2:1:1 Shaped Building Geometry. $b=0.08 \mathrm{~m}$. The Velocity Profile is $U=z^{0.27}$ (Yoshie et al., 2007). The Roof and Rear Reattachment Lengths are Defined as $X_{R}$ and $X_{F}$ Respectively
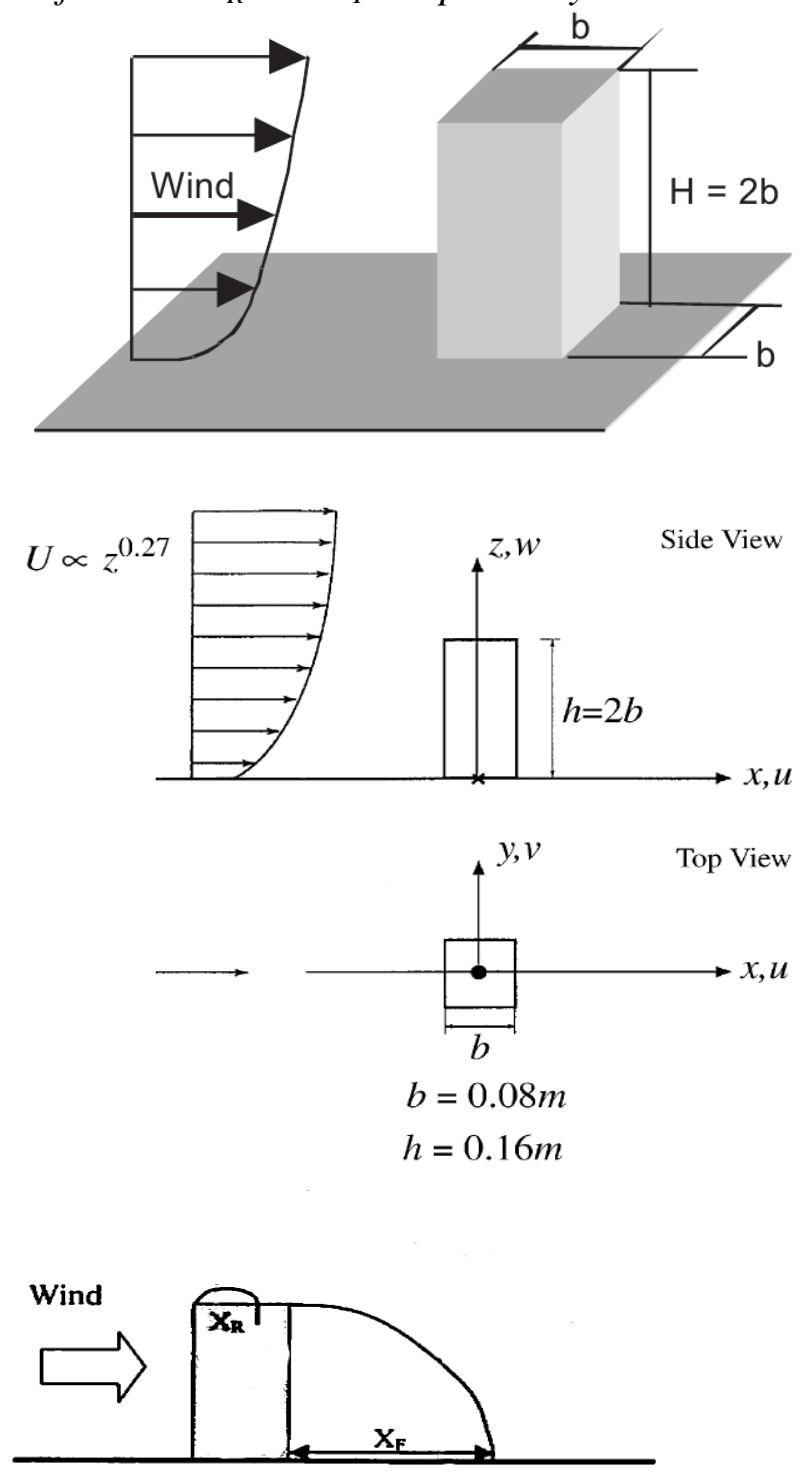
Figure 4. The Test Case A Wind Tunnel Experiment. (a) Measuring Points in Vertical Cross-section $(y=0)$. (b) Measuring Points in Horizontal Plane $(z=$ $0.125 b$ and 1.25b) (Yoshie et al., 2007)

a
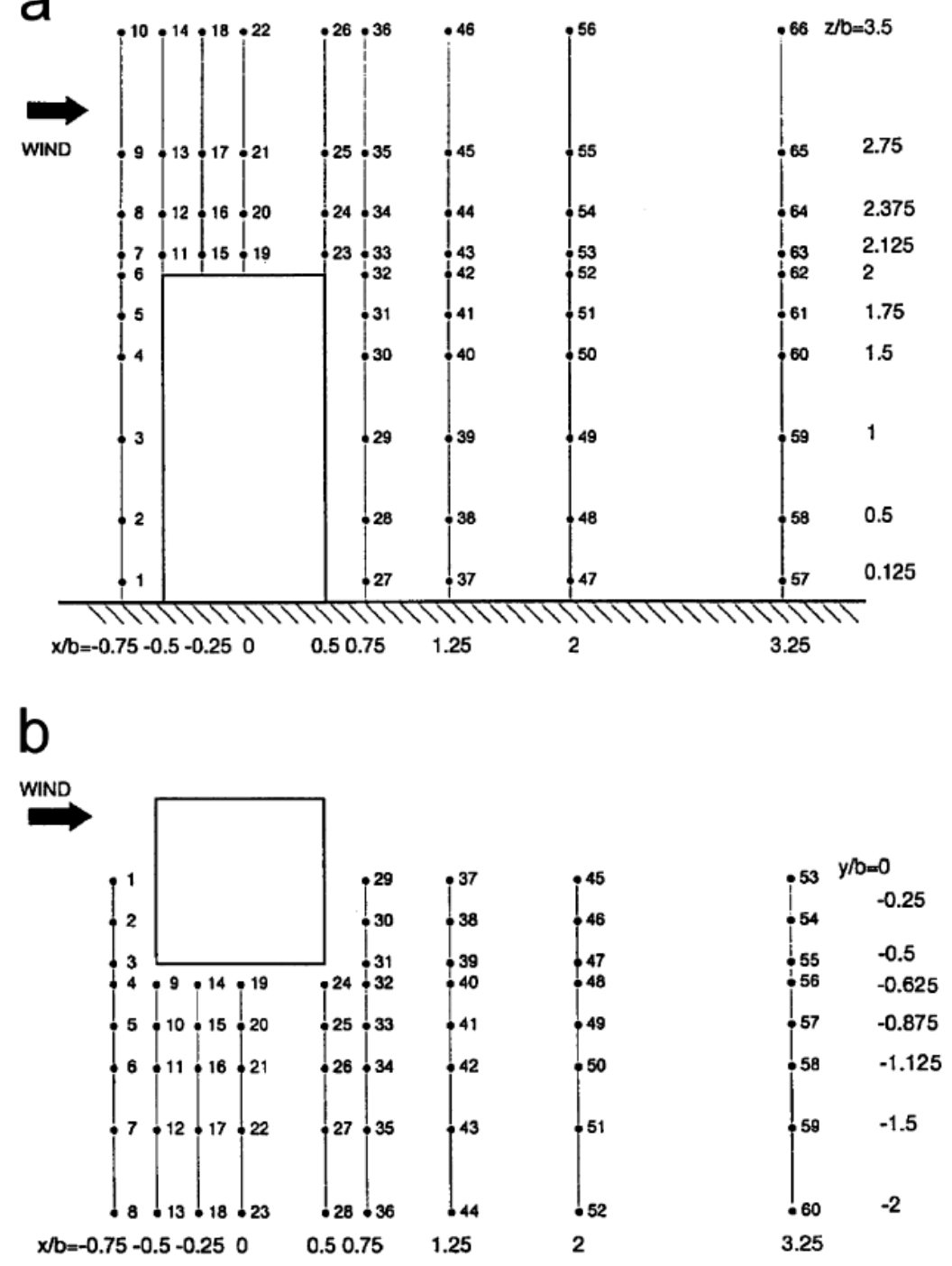

Computational Domain and Mesh

The dimensions of the computational domain are $\mathrm{L} \times \mathrm{W} \times \mathrm{H}=21 \mathrm{~b} \times$ 13.75b x 11.25b (with $b$ being the width of the building)(Figure 5) and replicate the geometry of the wind tunnel-as recommended in best practice guidelines Franke et al., 2007. The experiment parameters have been reported by Tominaga et al., 2008 and are the standard conditions for the comparative studies with the wind tunnel data as well as the CFD results of other working groups. 
Figure 5. Computational Domain

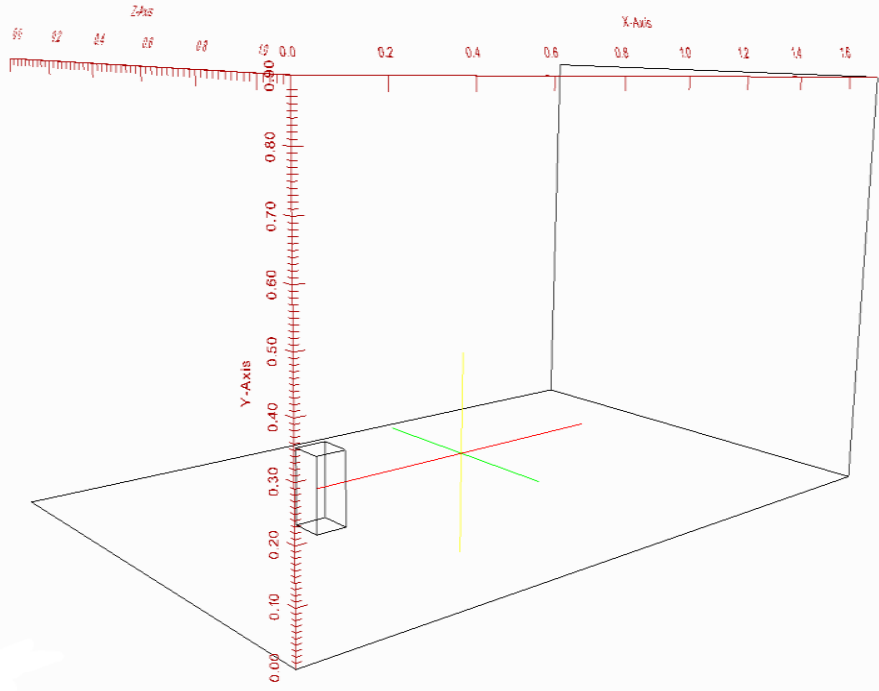

\section{Boundary Conditions}

The conditions shown in Table 1 are the standard boundary conditions for the RANS calculations - following the practices reported by Yoshie et al., 2007. For the Spalart-Allmaras DES calculations, we had to assign conditions for the velocity, the pressure, the subgrid scale viscosity (nuSgs) and the turbulent variable nuTilda. At the lateral and upper surfaces symmetry conditions were applied. For the walls a fixed value constant velocity of $u=0$ was used, a zero gradient for the pressure, the nuTilda was equal to zero and a wall function was applied for the nuSgs. At the outlet the pressure was set to zero and zerogradient conditions were applied to the rest of the quantities. Interpolated values of $U$ were applied to the inlet, the pressure was set to zerogradient and fixed values were used for the nuTilda and nuSgs.

The mesh resolution for the RANS calculations was $60(\mathrm{x}) \times 45(\mathrm{y}) \times 39(\mathrm{z})$ $(105,300$ cells $)$ and the building was discretized into $10 \times 10 \times 16$. The minimum grid width is set to $0.07 \mathrm{~b}$ and is expanded towards the horizontal and vertical directions. This follows similar practices with other CFD studies of this case reported by Tominaga et al., 2008. A finer mesh was used for the DES calculations and contained approximately 1.1 million cells. Figure 6 illustrates these mesh arrangements. 
Vol. 3, No. 2 Dadioti et al.: Validation of a Detached Eddy Simulation (DES)...

Figure 6. Test Case A Grid Discretization for: (a) DES Cases; (b, c) RANS Cases

a

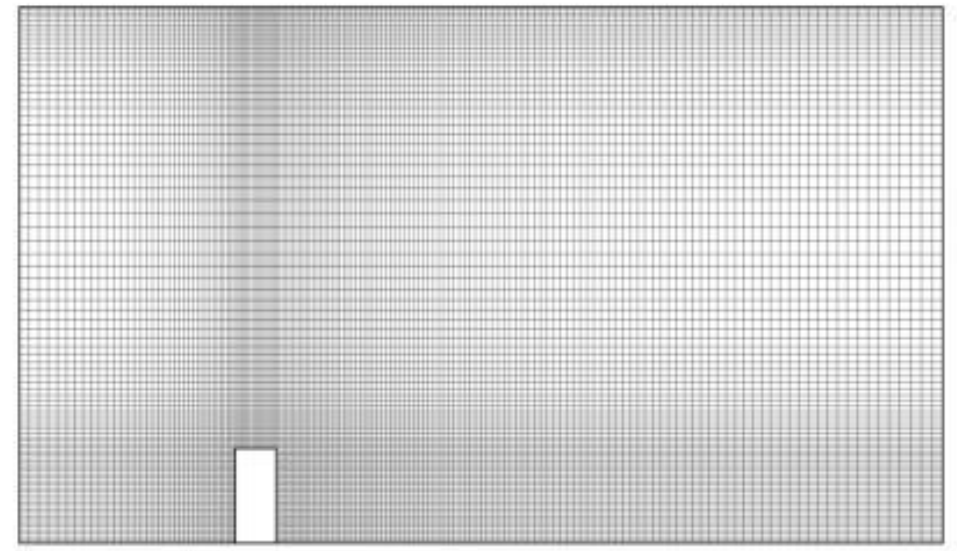

b

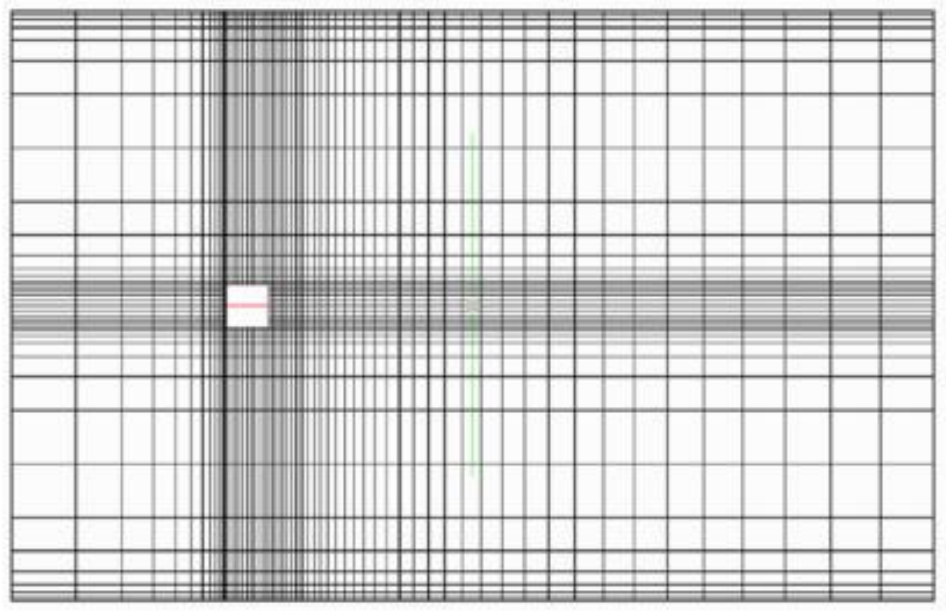

C

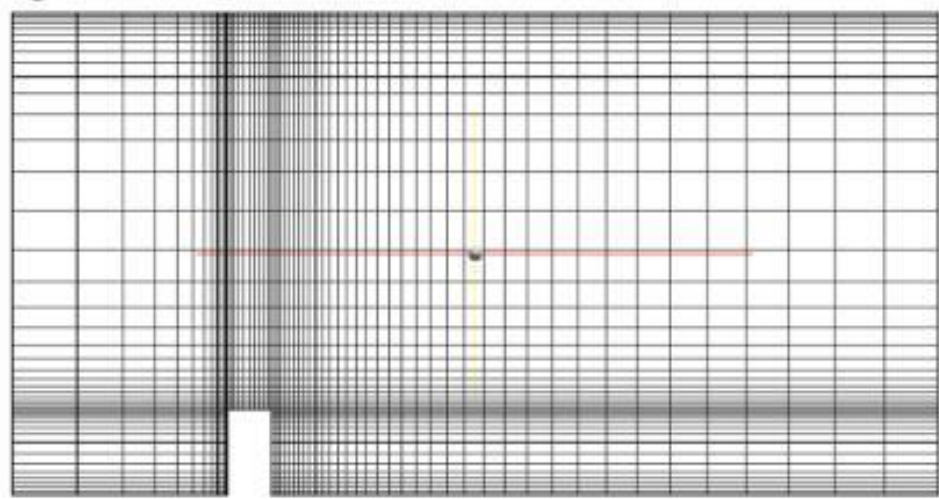




\section{Test Case B: Actual Urban Area}

\section{General Description of the Experiment}

The second test case is a study of the flow field within a building complex in the Shinjuku sub-central area of Tokyo, Japan (Figure 7). A number of wind tunnel experiments as well as field measurements were carried out by various research institutions during the time of construction. In this and other reported studies the CFD simulations were performed for conditions recorded in 1977 (Yoshie et al., 2007). The case is of particular interest since it has a complex geometry with large variation in building heights. The data set has additional value as it includes field measurements as well as wind tunnel test data. In the field tests three cup anemometers were used, taking measurements at $10 \mathrm{~m}$ height from the ground for the points 1 to 36 and at $192 \mathrm{~m}$ and $242 \mathrm{~m}$ for the $\mathrm{C}$ and D points shown in Figure 8.

Table 1. Standard Boundary Conditions (Yoshie et al., 2007)

\begin{tabular}{ll} 
Inflow & Interpolated values of $\mathrm{U}$ and $\mathrm{k}$ from the experimental flow \\
Outflow & Zero gradient \\
Lateral and upper surfaces of the domain & Logarithmic law for a smooth wall \\
Ground surface & Logarithmic law with roughness length $\mathrm{z}_{\mathrm{o}}\left(\mathrm{z}_{0}=1.8 \times 10^{4} \mathrm{~m}\right)$ \\
Upper surface & Logarithmic law for a smooth wall \\
\hline
\end{tabular}

Figure 7. Building Complexes in Urban Area of Shinjuku (Yoshie et al., 2007) that Define the Geometry of Test Case B

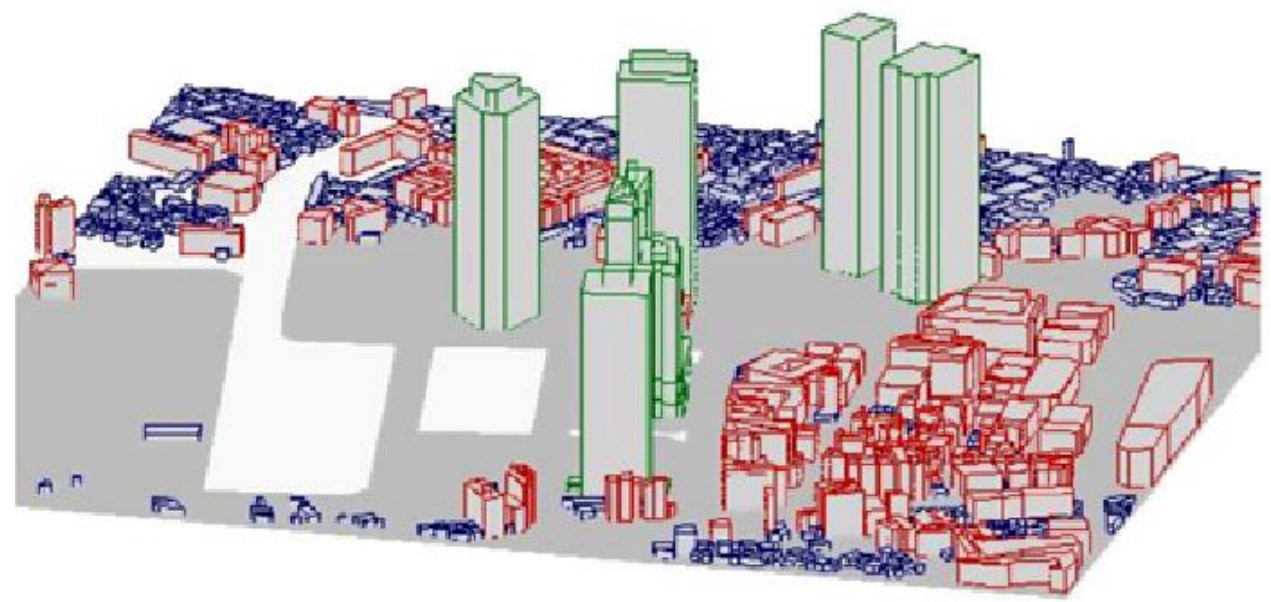


Figure 8. Test Case B Measuring Points and Building Heights (Shinjuku)

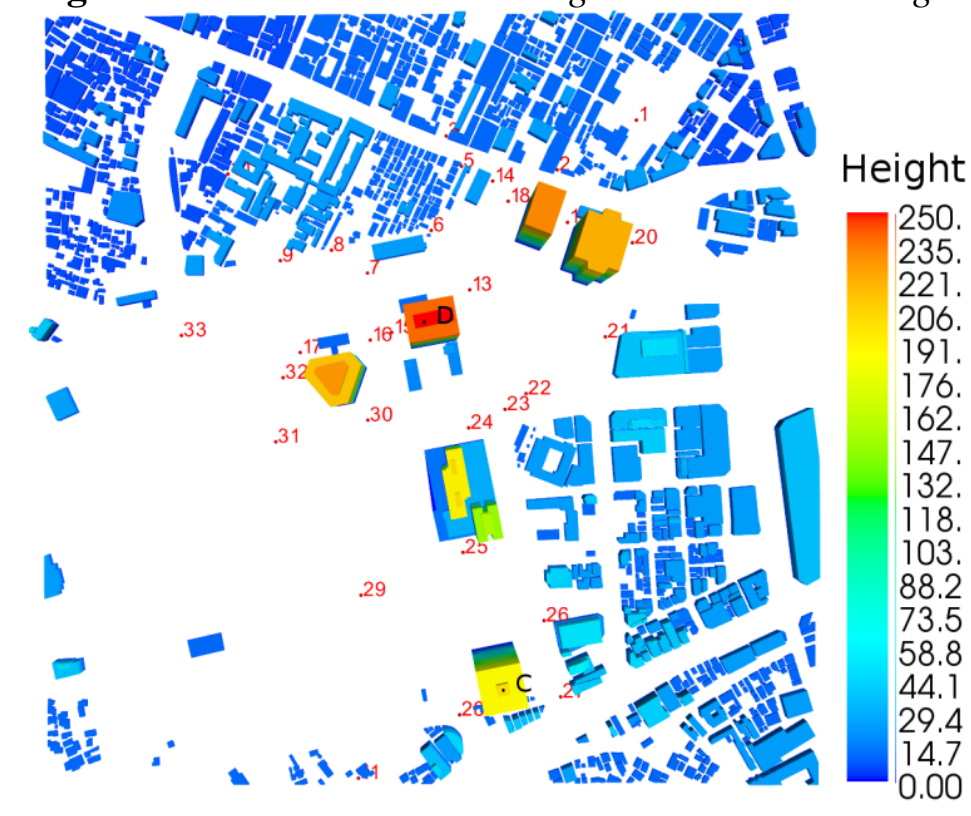

Computational Domain and Mesh

The computational domain is firstly defined by the CAD data representing $1000 \times 1000 \mathrm{~m}$ of the Shinjuku subcentral area (Figure 8). This building geometric data extends for approximately one block beyond the central region containing the measurement points (the exception being point 11 close to the south border) and follows the AIJ guidance (Yoshie et al., 2007). The dimensions of the complete domain are $\mathrm{L} \times \mathrm{W} \times \mathrm{H}=5742 \times 3372 \times 1422 \mathrm{~m}^{3}$ accommodating an upstream length of $5 \mathrm{H}$ (with $\mathrm{H}$ being the height of the highest building), a downstream subdomain length of $15 \mathrm{H}$ and a height of $6 \mathrm{H}$. The lateral boundaries have been placed $5 \mathrm{H}$ from the Shinjuku partition in accordance with the best practice guidelines (Franke et al., 2007; Tominaga et al., 2008) (Figure 9).

Figure 9. Computational Domain

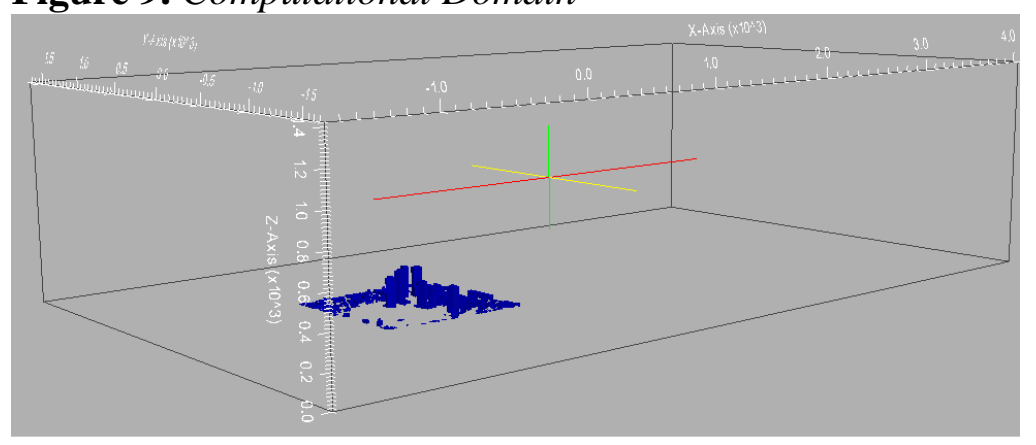

This case study has a geometric complexity representative of urban environments of practical interest and represents a challenge in terms of mesh generation. Parts of the computational grid are presented in Figure 10 to 
demonstrate the refinement regions around the buildings. The boundary conditions were treated in a similar manner to Test Case A.

Figure 10. Parts of the Computational Grid
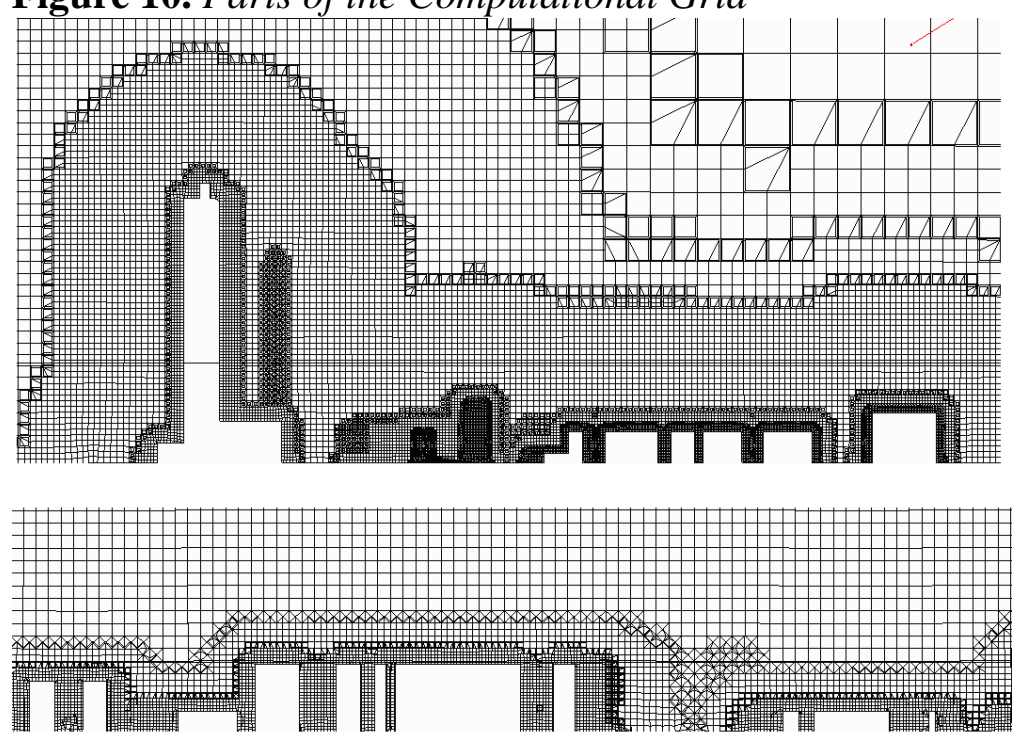

\section{Results}

\section{Test Case A Results}

The experimental data for Test Case A, and the results of other related CFD studies, are available in the form of predictions of reattachment lengths $\left(\mathrm{X}_{\mathrm{F}}\right.$ and $\mathrm{X}_{\mathrm{R}}$ in Figure 3 ) and mean velocities at a the grid of points shown in Figure 4. A synopsis of the computed reattachment lengths is presented in Table 2. These are the CFD results for the RANS simulations utilizing different turbulence models and the hybrid DDES-SA model with reattachment lengths estimated from examining the mean longitudinal wind velocities near the roof and ground surfaces.

Table 2. Test Case A Results: Computed Reattachment Length

\begin{tabular}{clccc}
\hline$\#$ & CFD model & Turbulence model & $\mathrm{x}_{\mathrm{F}} / \mathrm{b}$ & $\mathrm{x}_{\mathrm{R}} / \mathrm{b}$ \\
1 & RANS & Standard k- $\varepsilon$ & 2.68 & 0.50 \\
2 & RANS & Realizable k- $\varepsilon$ & 5.37 & 0.50 \\
3 & RANS & k- $\omega$ SST & 2.59 & 0.30 \\
4 & LES/RANS & DDES-SA & 2.39 & 0.38 \\
5 & Experiment & & 1.42 & 0.52 \\
\hline
\end{tabular}

In all cases the rear reattachment lengths are over predicted with the prediction of the DDES-SA calculation being the closest to the experimental value. Tominaga et al. (2004) presented 11 sets of results for this test case and also found that $\mathrm{X}_{\mathrm{F}} \mathrm{f}^{\mathrm{b}}$ was over predicted (a range of 1.98-2.7 for different implementations of the standard $\mathrm{k}-\varepsilon$ model). Lower values closer to the experimental result were only found using LES or DNS approaches in the 
study. The behaviour in the wake is further illustrated in Figure 12. This shows similar features in the standard k- $\varepsilon$ and DDES-SA flow near the reattachment point. However, there are further differences/further downstream as the flow returns towards its undisturbed condition-unfortunately no wind tunnel measurements are available for this region so we cannot comment further.

The recirculation zone near the leading edge of the roof and the associated reattachment length $\left(x_{R}\right.$ in Figure 3$)$, which was observed in the wind tunnel experiments, was only reproduced in the RANS calculations with the k- $\omega$-SST turbulence model (Table 2). The DDES-SA and other RANS results show the flow attached over part of the roof, but no clear reversal of flow. Similar variability in the prediction of this feature was noted by Tominaga et al. (2004).

Figure 11 presents the distribution of the mean horizontal velocity $\left(\overline{\mathrm{U}}_{\mathrm{x}}\right)$ on a vertical mid plane $(y=0)$ and on two horizontal planes. One horizontal plane is near the ground $(\mathrm{z}=0: 125 \mathrm{~b})$ and one part way up the building $(\mathrm{z}=1: 25 b)$. The positions of the measuring lines are illustrated with the dotted lines which also represent the origin for the calculated wind velocities, i.e. positive values are plotted on the right side of the line, and negative values on the left side (Yoshie et al., 2007).

In general, where the mean velocities are compared at the measurement points (Figure 11) there is a good correspondence between the CFD results and the wind tunnel data. The main differences in these velocity profiles are found near the building surfaces and the edges of the wake i.e. at locations of higher velocity gradient or rates of shear. The DDES-SA results and Standard k- $\varepsilon$ turbulence model results generally show the best agreement with the experimental data. In the horizontal plane part way up the building $(z=1: 25 b)$, horizontal velocities are noticeably underestimated inside the wake region. In the horizontal plane near the ground surface $(z=0: 125 b)$, the DDES-SA results are noticeably better than all the RANS models. 
Figure 11. Distribution of $\overline{\mathrm{U}}_{\mathrm{x}}$ in a Vertical Plane on the Centreline (a) and in Horizontal Planes at Heights $0.125 b$ and $1.25 b$
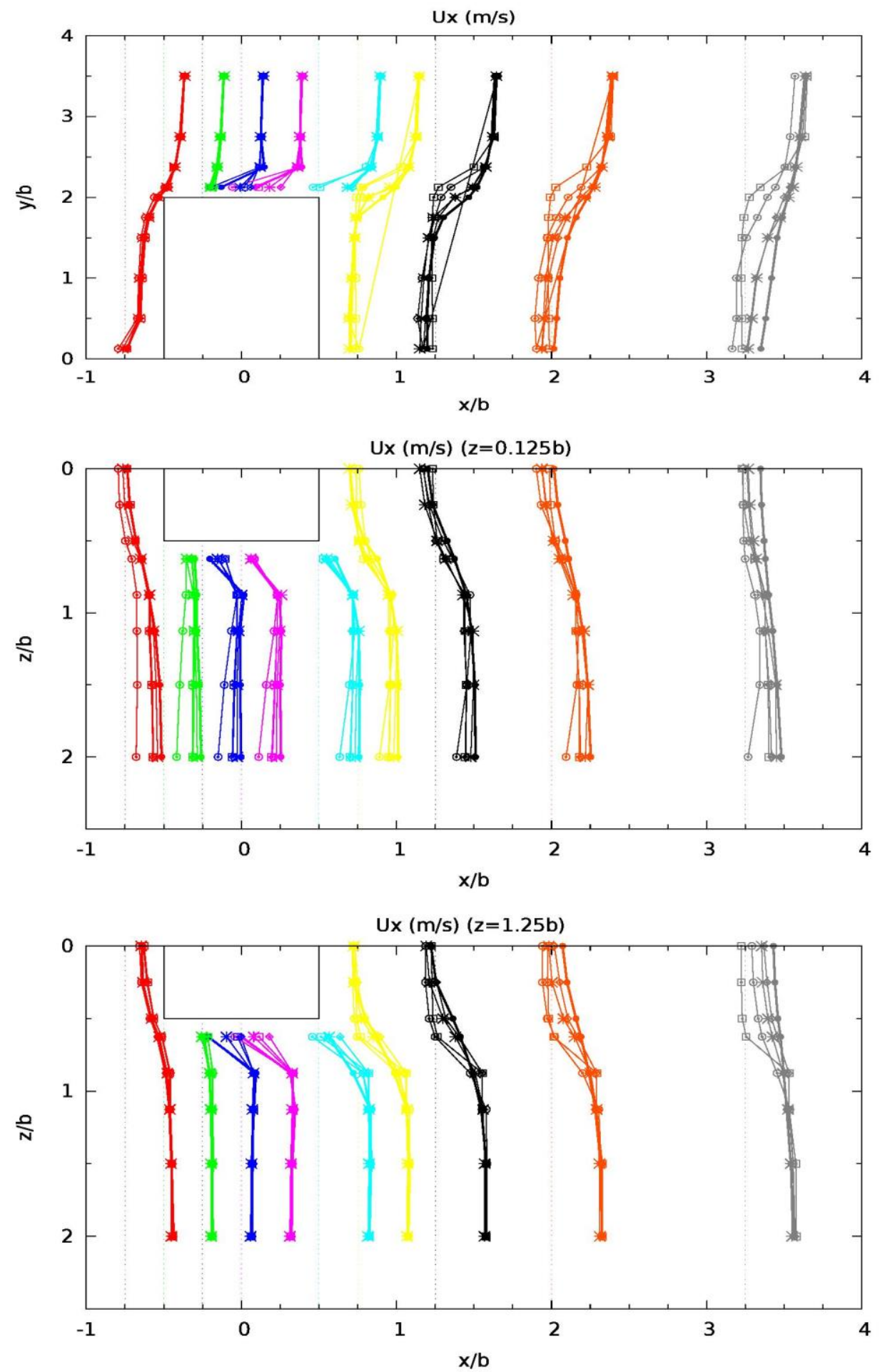

Wind Tunnel data

CFD Standard k- $\varepsilon$

CFD k- $\omega$ SST

CFD DDES

CFD Realizable $\mathrm{k}-\varepsilon$

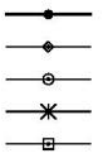


Visualisation of the instantaneous velocities calculated with the DDES-SA model has given some insight into the behaviour in the wake region. The aspect ratio of the building means that the eddy structures generated by the vertical leading edges dominate those generated at the leading edge of the roof. The largest eddy structures flowing from the roof are transported over the eddy structures near the ground at the leeward side of the building. The flow in the wake region accordingly seems more complex, with stronger mixing than the flows over the cubes. This has also been pointed out by Tominaga et al. (2004). It appears that consequently there are periods in the vortex shedding cycle where the wake is extended and the reattachment point is very mobile. This gives some clue as to why it was difficult to achieve convergence with the Realizable model. This is to be investigated further.

Figure 12. Velocity Vectors and Magnitude Data on a Vertical Plane through the Centre of the Wake Region

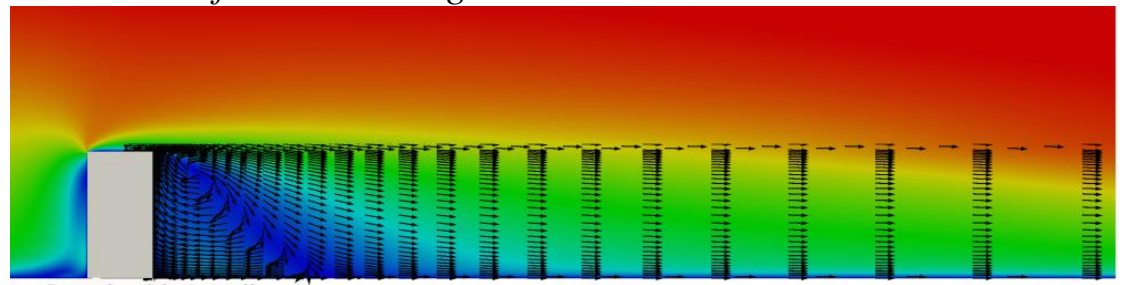

a. Standard k - epsilon

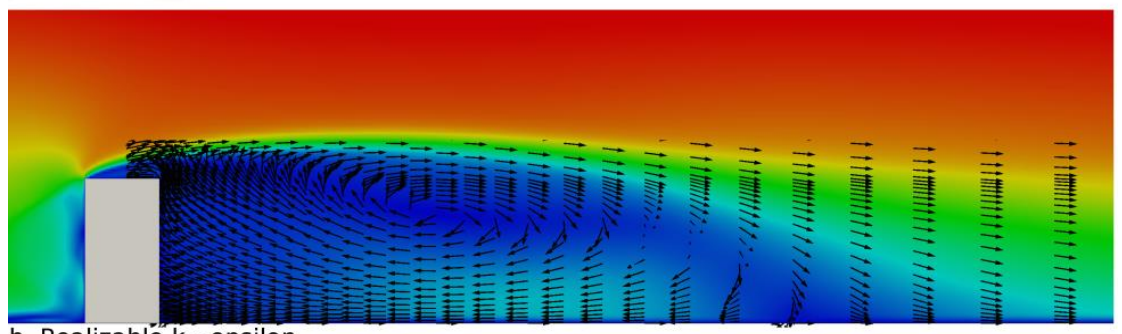

b. Realizablè k - epsilon
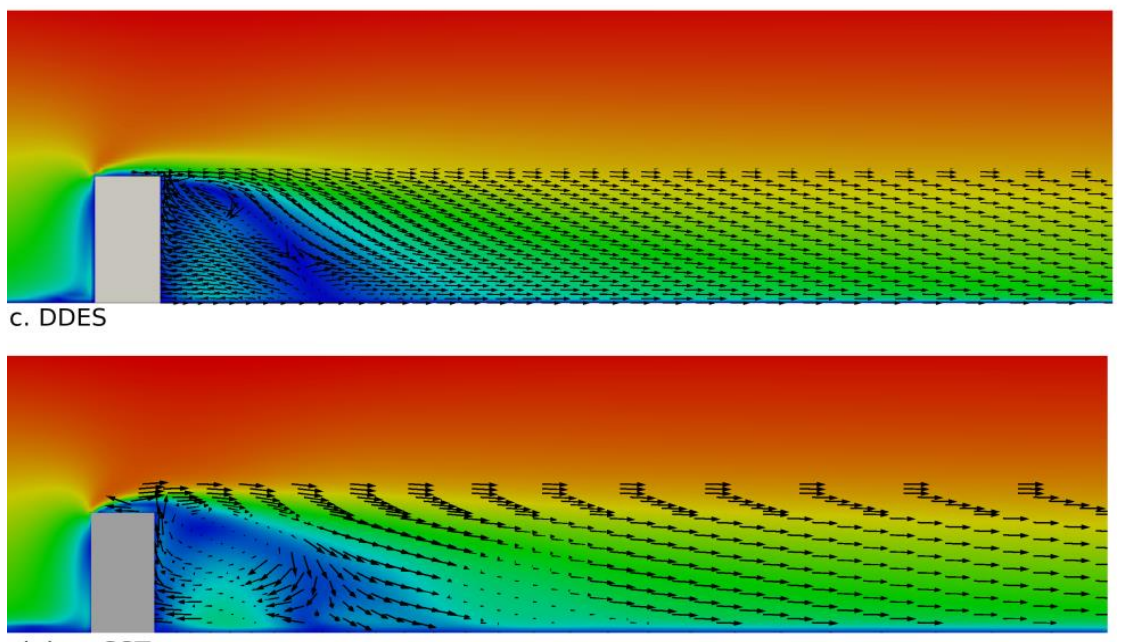

d. $k-\omega-S S T$

Velocity Magnitude

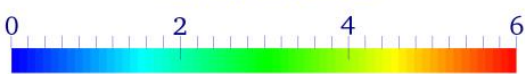




\section{Test Case B Results}

To compare the CFD results with the field measurements and the wind tunnel data, the computational wind speed has been normalised by the wind speed at reference point D (the top of the Shinjuku Mitsui Building) at a height of $242 \mathrm{~m}$ for the north wind direction and point $\mathrm{C}$ (the top of the KDD Building) at a height of $192 \mathrm{~m}$ for the other wind directions as in previous studies.

Figure 13 presents the calculated wind speed ratios alongside the field measurements and the wind tunnel data (where available), at the measuring points for four wind directions (East, South, West and North). In 44 of the total of 60 comparisons, the results for the DDES-SA model fall within one standard deviation of the field measurements and only 5 fall significantly outside this band. The RANS results fall outside the one standard deviation band in 24 out of a total of 60 tests - 12 are significantly outside.

The superior performance of the DDES-SA model is also demonstrated in Figure 14, where the results are compared with the RANS results for other CFD codes published by a working group of the Architectural Institute of Japan (Tominaga et al., 2005). In this figure the measurement points are shown in order of increasing mean velocity.

A qualitative review of the results (Figure 15) shows that the complex flow patterns of the interaction between the wind flow and building is well reproduced by the DDES-SA calculations, including such details as the horseshoe vortex shape (h1, h2 and h3 regions) and the reattachment zones behind the buildings (r1, r2 and r3 regions). In the RANS results (Figure 15 right) these vortices are not as well defined and the size of the recirculation zone in the wake of the buildings is overestimated. 
Vol. 3, No. 2 Dadioti et al.: Validation of a Detached Eddy Simulation (DES)...

Figure 13. Comparison of Predicted and Measured Wind Speed Ratios at the Reference Measuring Points. The North and South Wind Directions Include Field Study Data.
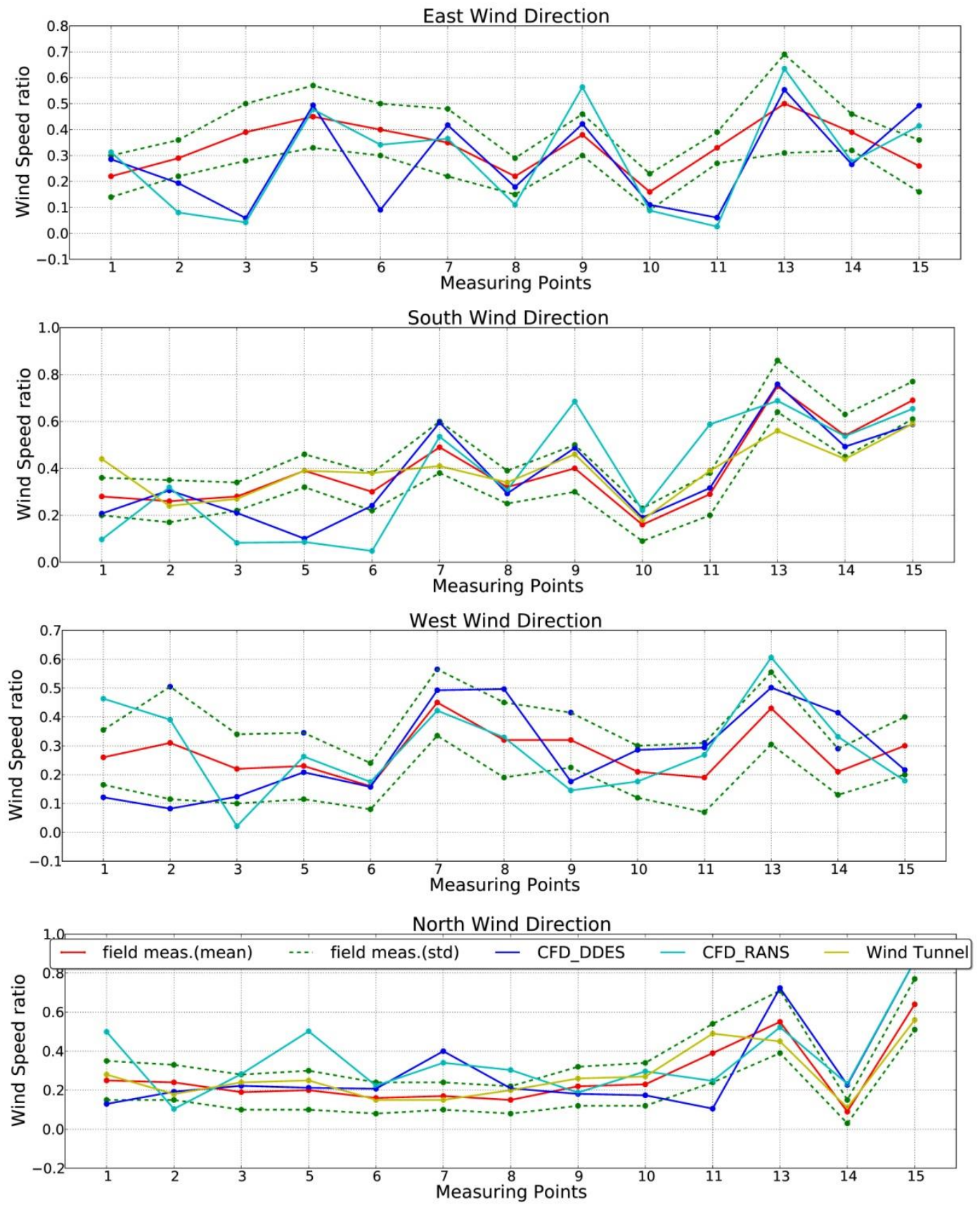
Figure 14. Comparison of Wind Speed Ratio at Reference Measuring Points with Wind Direction South

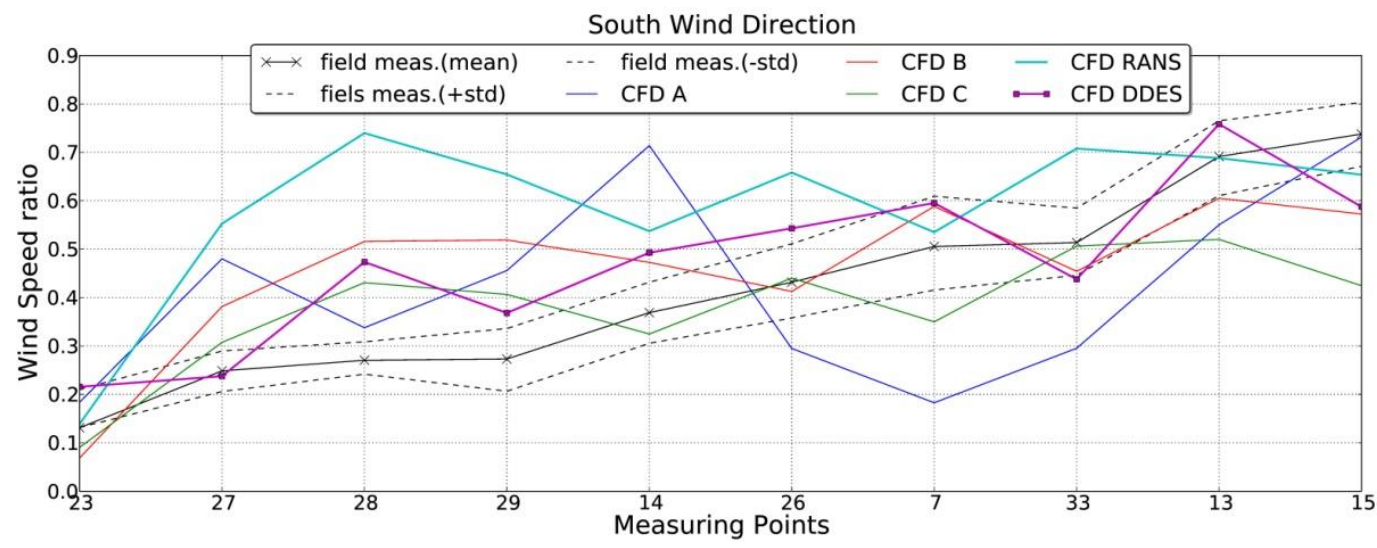

Figure 15. Vectors of the Wind Velocity at a Plane 10m above the Ground for the DDES-SA Model (Left) and the RANS Model (Right)

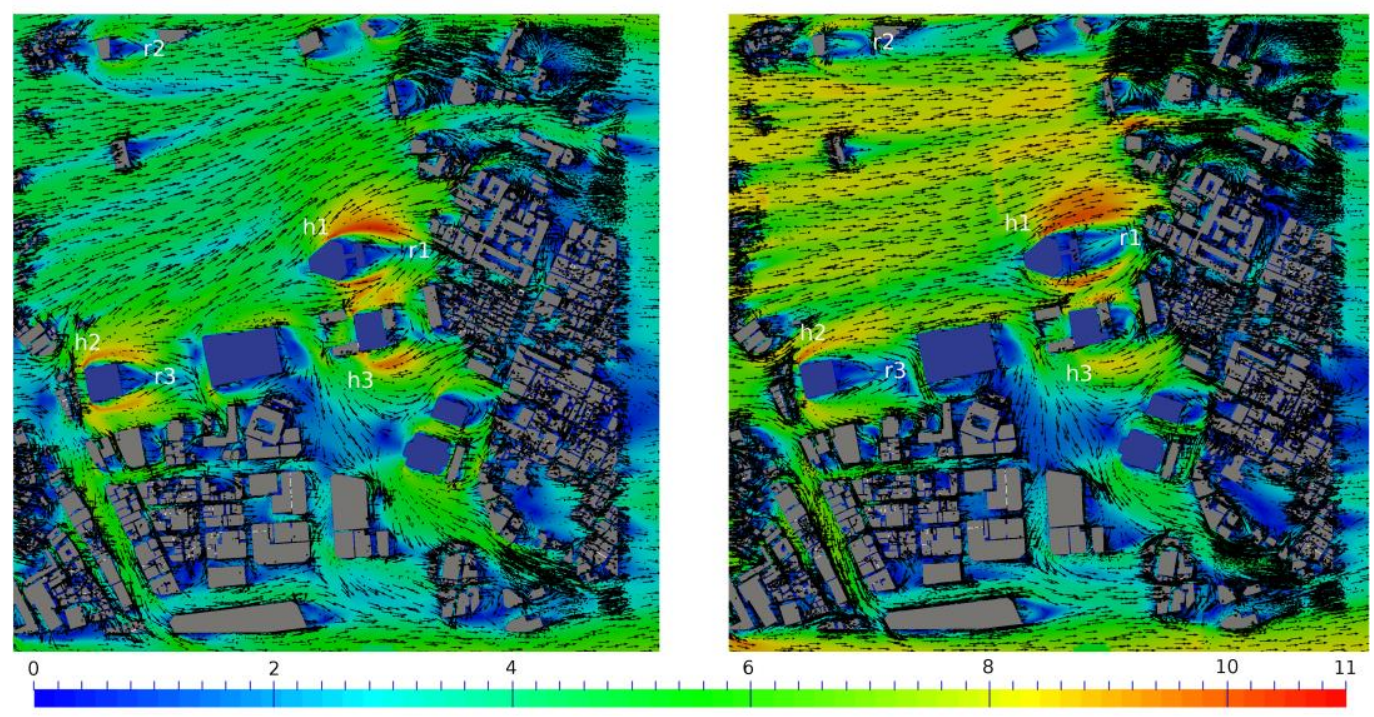

\section{Conclusions}

In this work we investigated the prediction capabilities of the numerical models implemented using the Open- FOAM CFD library and revisiting two test cases developed by the Architectural Institute of Japan that provide benchmark data derived from wind tunnel testing and field measurements. The test cases represent an idealized building with 2:1:1 aspect ratios and a real urban geometry with considerable geometric complexity. The tests have examined the mean velocity predictions and boundary layer reattachment lengths. We examined the performance of both steady-state RANS approaches with some eddy-viscosity turbulence models as well as a hybrid RANS/LES approach with the Delayed Detached Eddy Simulation (DDES-SA) turbulence model. 
Calculations of wind flows around buildings using RANS approaches and two-equation turbulence models are known to have limitations, particularly in calculating conditions in wake regions. We found this to be the case with the models of this type we evaluated using OpenFOAM and that predictions were comparable with what has been published in earlier studies for these types of models. Results from applying DES approaches to these test cases have not been published before. The results we obtained with the DDES-SA model have been noticeably better than those from the RANS models, particularly in the wake regions where LES is the mode of calculation. We concluded that this approach, although significantly more computationally demanding than RANS calculations, offers improved robustness and accuracy over a range of wind conditions. Accordingly, we intend to pursue the application of DES approaches using OpenFOAM in the further study of wind flows at the campus where we are collecting high frequency anemometer data for further validation exercises.

\section{Future Work}

To validate the CFD predicted results, simulations will be performed for a total of 16 directions for the Shinjuku sub central model. Adequate field measurements are available, thus a comprehensive study can reveal with confidence the prediction capabilities of the DDES to support the application of CFD for other complex urban configurations. Next, we will apply the DDES approach to the De Montfort University campus case study in Leicester, United Kingdom, combining statistical meteorological data with aerodynamic information and using the wind measurements taken since January 2015 using 3 ultrasonic anemometers.

\section{Nomenclature}

\begin{tabular}{|c|c|c|c|c|c|}
\hline \multicolumn{3}{|c|}{ Acronyms } & \multicolumn{3}{|c|}{ Mathematical Symbols } \\
\hline $\mathrm{AIJ}$ & \multicolumn{2}{|l|}{ Architectural Institute of Japan } & \multicolumn{3}{|c|}{$\nabla \quad$ nabla operator } \\
\hline CFD & \multicolumn{2}{|l|}{ Computational Fluid Dynamics } & \multicolumn{3}{|c|}{ Roman Symbols } \\
\hline DES & \multicolumn{2}{|l|}{ Detached Eddy Simulation } & $\bar{u}$ & filtered velocity & {$\left[\mathrm{ms}^{-1}\right]$} \\
\hline DDES & \multicolumn{2}{|l|}{ Delayed Detached Eddy Simulation } & f & body forces per unit volume & {$\left[\mathrm{Nm}^{-3}\right]$} \\
\hline DNS & \multicolumn{2}{|l|}{ Direct Numerical Simulation } & $\mathrm{u}$ & fluid flow velocity & {$\left[\mathrm{ms}^{-1}\right]$} \\
\hline LES & \multicolumn{2}{|l|}{ Large Eddy Simulation } & $\rho$ & density & {$\left[\mathrm{kgm}^{-3}\right]$} \\
\hline RANS & \multicolumn{2}{|l|}{ Reynolds-Averaged Navier Stokes } & CDES & empirical constant & {$[-]$} \\
\hline SA & \multicolumn{2}{|l|}{ Spalart Allmaras turbulence model } & $d w$ & wall distance & {$[\mathrm{m}]$} \\
\hline SST & \multicolumn{2}{|l|}{ Shear Stress Transport } & IDES & DES model length scale & [m] \\
\hline $\begin{array}{l}\text { URAN } \\
S\end{array}$ & Unsready Reynolds-Averaged & Stokes & e & $\begin{array}{l}\text { total specific internal } \\
\text { energy }\end{array}$ & {$\left[\mathrm{m}^{2} \mathrm{~s}^{-2}\right]$} \\
\hline \multicolumn{3}{|c|}{ GreekSymbols } & $\mathrm{k}$ & turbulence kinetic energy & {$\left[\mathrm{m}^{2} \mathrm{~s}^{-2}\right]$} \\
\hline$\Delta$ & filter width & {$[\mathrm{m}]$} & P & mean pressure & {$\left[\mathrm{Nm}^{-2}\right]$} \\
\hline$\mu$ & \multicolumn{2}{|l|}{ dynamic viscosity } & $\mathrm{p}$ & pressure & {$\left[\mathrm{Nm}^{-2}\right]$} \\
\hline$v$ & \multicolumn{2}{|l|}{ kinematic viscosity } & $\mathrm{q}$ & energy source term & {$\left[\mathrm{m}^{2} \mathrm{~s}^{-2}\right]$} \\
\hline$\omega$ & $\begin{array}{l}\text { Specific turbulence dissipation } \\
\text { rate }\end{array}$ & {$\left[\mathrm{s}^{-1}\right]$} & t & time & [s] \\
\hline$\tau_{i j}{ }^{R}$ & \multirow{3}{*}{$\begin{array}{l}\text { unresolved stress tensor } \\
\text { turbulence dissipation }\end{array}$} & \multirow{3}{*}{$\begin{array}{r}{\left[\mathrm{kgm}^{-1} \mathrm{~s}^{-2}\right.} \\
{\left[\mathrm{m}^{2} \mathrm{~s}^{-3}\right]}\end{array}$} & $\mathrm{U}$ & mean velocity & {$\left[\mathrm{ms}^{-1}\right]$} \\
\hline$\varepsilon$ & & & $\mathrm{u}$ & fluctuating part of velocity & {$\left[\mathrm{ms}^{-1}\right]$} \\
\hline & & & $\mathrm{x}$ & position vector & {$[\mathrm{m}]$} \\
\hline
\end{tabular}




\section{References}

AIAA 1998. Guide for the Verification and Validation of Computational Fluid Dynamics Simulations (AIAA G-077-1998(2002)). American Institute of Aeronautics and Astronautics, Inc.

AIJ 2009. Guidebook for Practical Application sof CFD to Pedestrian Wind Environment around Buildings. Available online [accessed 12/5/15] http://www.aij.or.jp/jpn/publish/cfdguide.

Anjum, L. 2014. Wind resource estimation techniques-an overview. International Journal of wind and Renewable Energy, 3(2):26-38.

Balogh, M., Parente, A., and Benocci, C. 2012. fRANSg simulation of fABLg flow over complex terrains applying an enhanced $\mathrm{k}-$ ? model and wall function formulation: Implementation and comparison for fluent and openfoam. Journal of Wind Engineering and Industrial Aerodynamics, 104?106:360 - 368. 13th International Conference on Wind Engineering.

Blocken, B. and Persoon, J. 2009. Pedestrian wind comfort around a large football stadium in an urban environment: CFD simulation, validation and application of the new Dutch wind nuisance standard. Journal of Wind Engineering and Industrial Aerodynamics, 97(5-6):255-270.

Blocken, B., Janssen, W., and van Hooff, T. 2012. CFD simulation for pedestrian wind comfort and wind safety in urban areas: General decision framework and case study for the Eindhoven University campus. Environmental Modelling and Software, 30:15-34.

Breuer, M., Jovii, N., and Mazaev, K. 2003. Comparison of des, rans and les for the separated flow around a flat plate at high incidence. International Journal for Numerical Methods in Fluids, 41(4):357-388.

Churchfield, M. J. and Moriarty, P. J. 2010. Wind energy-related atmospheric boundary layer largeeddy simulation using openfoam. In 19th Symposium on Boundary Layers and Turbulence, Keystone, Colorado.

Coirier, W. J. and Kim, S. 2006. Cfd modeling for urban area contaminant transport and dispersion: Model description and data requirements. In American Meteorological Societys 6th Symposium on the Urban Environment, Atlanta, GA, Amer. Meteor. Soc., JP2, volume 11.

Colloquium, C. C. 2013. Computational Fluid Dynamics Approach for Wind Analysis of Highrise Buildings Computational Fluid Dynamics Approach for Wind Analysis of Highrise Buildings. (January).

Fadl, M. S. and Karadelis, J. 2013. CFD Simulation for Wind Comfort and Safety in Urban Area: A Case Study of Coventry University Central Campus. International Journal of Architecture, Engineering and Construction, 2(2):131-143.

Flores, F., Garreaud, R., and Muoz, R. C. 2014. Openfoam applied to the fCFDg simulation of turbulent buoyant atmospheric flows and pollutant dispersion inside large open pit mines under intense insolation. Computers Fluids, 90:72 - 87.

Franke, J., Hirsch, C., Jensen, A., Krus, H., Schatzmann, M., Westbury, P., Miles, S., Wisse, J., and Wright, N. 2004. Recommendations on the use of CFD in wind engineering, COST Action C14. European Science Foundation COST Office.

Franke, J., Hellsten, A., Schlunzen, H., and Carissimo, B. 2007. Best practice guideline for the CFD simulation of flows in the urban environment, COST Action 732. European Science Foundation COST Office.

Gagliano, A., Nocera, F., Patania, F., and Capizzi, A. 2013. Assessment of micro-wind turbines performance in the urban environments: an aided methodology through 
geographical information systems. International Journal of Energy and Environmental Engineering, 4(1):43.

Ghione, A. 2012. Development and validation of a two-phase cfd model using openfoam. Master's thesis, KTH, Stockholm.

Holmes, N. and Morawska, L. 2006. A review of dispersion modelling and its application to the dispersion of particles: An overview of different dispersion models available. Atmospheric Environment, 40(30):5902-5928.

Hooff, T. V. and Blocken, B. 2010. On the effect of wind direction and urban surroundings on natural ventilation of a large semi-enclosed stadium. Computers \& Fluids, 39(7):1146-1155.

Huang, S. and Li, Q. 2010. Numerical simulations of wind-driven rain on building envelopes based on eulerian multiphase model. Journal of Wind Engineering and Industrial Aerodynamics, 98(12):843 - 857.

Irshad, W. 2012. Wind resource assessment: statistical and computational fluiddynamic analysis. $\mathrm{PhD}$ thesis, Edinburgh Napier University.

Janssen, W., Blocken, B., and van Hooff, T. 2013. Pedestrian wind comfort around buildings: Comparison of wind comfort criteria based on wholeflow field data for a complex case study. Building and Environment, 59(0):547 - 562.

Jasak, H., Jemcov, A., and Tukovic, Z. 2007. Openfoam: A c++ library for complex physics simulations. International workshop on coupled methods in numerical dynamics, 1000:1-20.

Kalmikov, A., Dupont, G., Dykes, K., and Chan, C. 2010. Wind power resource assessment in complex urban environments: Mit campus case-study using cfd analysis. In AWEA 2010 WINDPOWER Conference. Dallas, USA.

Katz, P. C. and Ag, S. Use of Computational Fluid Dynamics in Civil Engineering. M.

King, K. 2009. Interim Report: Wind Speed and Energy Yield Analysis of Small Wind Turbines on a $45 \mathrm{~m}$ High-rise Building in the Built Environment. Technical report, Loughborough University.

Launder, B. and Spalding, D. 1974. The numerical computation of turbulent flows. Computer Methods in Applied Mechanics and Engineering, 3(2):269 - 289.

Mcalpine, J. D. 1985. Computational fluid dynamics or wind tunnel modeling?

Meng, Y. and Hibi, K. 1998. Cooperative project for CFD prediction of pedestrian wind environment in the architectural institute of japan. Journal of Wind Engineering, Japan, 76:55-64.

Menter, F. R. 1994. Two-equation eddy-viscosity turbulence models for engineering applications.

Meroney, R. N., d Neff, D. E., Chang, C.-h., and Pradoto, R. 2001. Computational Fluid Dynamics and Physical Model Comparisons of Wind Loads and Pedestrian Comfort Around a High Rise Building. In Inaugural Meeting of Wind Engineering Research Center, Tokyo Institute of Polytechnics, (TIP), Atsugi, Japan, October 20, page 2.

Milanese, M., de Risi, A., and Laforgia, D. 2011. Experimental and fluid-dynamic analysis of a micro wind turbine in urban area. In Proceedings of Worlds Renewable Energy Congress, Sweden, pages 4106-4113.

Moeng, C.-H. and Sullivan, P. 2015. Numerical models: Large-eddy simulation. In Zhang, G. R. N. P., editor, Encyclopedia of Atmospheric Sciences (Second Edition), pages 232 - 240. Academic Press, Oxford, second edition edition.

Mohotti, D., Mendis, P., and Ngo, T. 2014. Application of computational fluid dynamics (cfd) in predicting the wind loads on tall buildings- a case study. In 23rd Australasian Conference on the Mechanics of Structures and Materials, Byron Bay, Australia. 
Moin, P. and Mahesh, K. 1998. Direct numerical simulation: A tool in turbulence research. Annual Review of Fluid Mechanics, 30(1):539-578.

Neofytou, P., Venetsanos, A., Vlachogiannis, D., Bartzis, J., and Scaperdas, A. 2006. CFD simulations of the wind environment around an airport terminal building. Environmental Modelling \& Software, 21(4):520 - 524. Urban Air Quality Modelling Urban Air Quality Modelling.

Peterka, J., Meroney, R., and Kothari, K. 1985. Wind flow patterns about buildings. Journal of Wind Engineering and Industrial Aerodynamics, 21(1):21 - 38.

Probst, O. and Cardenas, D. 2010. State of the Art and Trends in Wind Resource Assessment. Energies, 3(6):1087-1141.

Rasouli, A., Romanic, D., and Hangan, H. 2014. Wind resource assessment in complex urban environments: case study. In Offshore Energy \& Storage Symposium, Windsor, Ontario, Canada UWCAES Society July 10-11.

Rudman, M. and Blackburn, H. 2006. Direct numerical simulation of turbulent nonnewtonian flow using a spectral element method. Applied Mathematical Modelling, 30(11):1229 - 1248. Selected papers from the Third International Conference on CFD in the Minerals and Process Industries 3rd International Conference on CFD Selected papers from the Third International Conference on CFD in the Minerals and Process Industries.

Sadiki, A., Maltsev, A., Wegner, B., Flemming, F., Kempf, A., and Janicka, J. 2006. Unsteady methods (urans and les) for simulation of combustion systems. International Journal of Thermal Sciences, 45(8):760 - 773.

Shih, T. 1994. A New K-epsilon Eddy Viscosity Model for High Reynolds Number Turbulent Flows: Model Development and Validation.

Spalart, P. R., Jou, W., Strelets, M., and Allmaras, S. R. 1997. Comments on the Feasibility of LES for Wings, and on a Hybrid RANS/LES Approach.

Spalart, P., Deck, S., Shur, M., Squires, K., Strelets, M., and Travin, A. 2006. A new version of detached-eddy simulation, resistant to ambiguous grid densities. Theoretical and Computational Fluid Dynamics, 20(3):181-195.

Stathopoulos, T. and Baniotopoulos, C. 2007. Wind Effects on Buildings and Design of Wind-Sensitive Structures. CISM International Centre for Mechanical Sciences. Springer.

Tabrizi, A. B., Whale, J., Lyons, T., and Urmee, T. 2014. Performance and safety of rooftop wind turbines: Use of CFD to gain insight into inflow conditions. Renewable Energy, 67:242-251.

Tominaga, Y., Mochida, A., Shirasawa, T., Yoshie, R., Kataoka, H., Harimoto, K., and Nozu, T. 2004. Cross Comparisons of CFD Results of Wind Environment at Pedestrian Level around a High-rise Building and within a Building Complex. Journal of Asian Architecture and Building Engineering, 3(1):63-70.

Tominaga, Y., Yoshie, R., Mochida, A., Kataoka, H., Harimoto, K., and Nozu, T. 2005. Cross comparisons of CFD prediction for wind environment at pedestrian level around buildings. comparison of results for fiowfield around building complex in actual urban area. In The Sixth Asia-Pacific Conference on Wind Engineering (APCWE-VI) Seoul, Korea.

Tominaga, Y., Mochida, A., Yoshie, R., Kataoka, H., Nozu, T., Yoshikawa, M., and Shirasawa, T. 2008. AIJ guidelines for practical applications of CFD to pedestrian wind environment around buildings. Journal of Wind Engineering and Industrial Aerodynamics, 96(10):1749 - 1761.

Tominaga, Y., Okaze, T., and Mochida, A. 2011. CFD modeling of snowdrift around a building: An overview of models and evaluation of a new approach. Building and Environment, 46(4):899 - 910. 
van Hooff, T., Blocken, B., Aanen, L., and Bronsema, B. 2011a. A venturi-shaped roof for wind-induced natural ventilation of buildings: Wind tunnel and CFD evaluation of different design configurations. Building and Environment, 46(9):1797-1807.

van Hooff, T., Blocken, B., and van Harten, M. 2011b. 3d CFD simulations of wind flow and wind-driven rain shelter in sports stadia: Influence of stadium geometry. Building and Environment, 46(1):22 - 37.

Vardoulakis, S., Fisher, B. E., Pericleous, K., and Gonzalez-Flesca, N. 2003. Modelling air quality in street canyons: a review. Atmospheric environment, 37(2):155-182.

Weller, H. G., Jasak, H., and Tabor, G. 1998. A tensorial approach to computational continuum mechanics using object-oriented techniques. Computers in Physics, 12(6):620-631.

Wendt, J., Anderson, J., and for Fluid Dynamics, V. K. I. 1996. Computational fluid dynamics: an introduction. Von Karman Institute book. Springer.

Willemsen, E. and Wisse, J. a. 2007. Design for wind comfort in The Netherlands: Procedures, criteria and open research issues. Journal of Wind Engineering and Industrial Aerodynamics, 95(9 - 11):1541-1550.

Woo, H., Peterka, J., Cermak, J., Aeronautics, U. S. N., and Administration, S. 1977. Wind Tunnel Measurements in the Wakes of Structures. NASA contractor report. National Aeronautics and Space Administration.

Yoshie, R., Mochida, A., Tominaga, Y., Kataoka, H., Harimoto, K., Nozu, T., and Shirasawa, T. 2007. Cooperative project for CFD prediction of pedestrian wind environment in the architectural institute of japan. Journal of Wind Engineering and Industrial Aerodynamics, 95(911):1551 - 1578. 